\title{
PERANCANGAN ARCHITECTURE ENTERPRISE SISTEM INFORMASI MANAJEMEN ASET DI BAGIAN UMUM KOTA BANDUNG (Studi Kasus : SETDA Kota Bandung)
}

\author{
Arif Bakti Nugraha \\ Pascasarjana Sistem Informasi, STMIK LIKMI Bandung \\ Email : arif.bakti5@gmail.com
}

Sekertaris Daerah (SETDA) Kota Bandung merupakan suatu instansi pemerintahan daerah yang memiliki tugas pokok dan fungsi untuk Mewujudkan Pelayanan Publik dan Pelayanan Aparatur yang Prima untuk menunjang Visi Kota Bandung sebagai Kota Bandung yang Unggul. Sekertaris Daerah Kota Bandung saat ini masih mengalami kesulitan dalam pengelolaan informasi yang berhubungan dengan inventerisir dan menejemen aset, sehingga perlu diupayakan pengelolaan informasi yang lebih baik, salah satu bentuk penerapannya yaitu melalui sistem informasi dengan memanfaatkan teknologi informasi berbasis komputer. Dalam teknologi informasi terdapat tiga bagian yang saling berhubungan, yaitu: perangkat keras, perangkat lunak, dan basis data. Perencanaan arsitektur sistem informasi yang terintegrasi dan sesuai dengan tujuan bisnis organisasi merupakan salah satu upaya untuk meningkatkan layanan ke arah yang lebih baik sehingga mampu bersaing dengan organisasi yang lain. Dalam penelitian ini membahas mengenai perencanaan arsitektur sistem informasi menejemen asset di bagian umum dan perlengkapan Kota Bandung, studi kasus di Sekertaris Daerah (SETDA) Kota Bandung. Pembahasan penelitian ini ditekankan pada empat tahap, yaitu: perencanaan arsitektur bisnis, perencanaan arsitektur data, perencanaan arsitektur aplikasi, dan perencanaan arsitektur teknologi. Hasil dari penelitian yang dilakukan yaitu perencanaan arsitektur sistem informasi menejemen aset di Sekertaris Daerah Kota Bandung, yang berupa rekomendasi pembangunan arsitektur sistem informasi guna menunjang perbaikan kinerja layanan publik dan integrasi sistem ke semua bagian yang ada dalam organisasi

Kata Kunci : Arsitektur Bisnis, Arsitektur Data, Arsitektur Aplikasi, Arsitektur Teknologi, EAP.

Regional Secretary (SETDA) of Bandung City is a local government agency that has the main tasks and functions to Realize Public Services and Excellent Service Personnel to support the Vision of Bandung City as the Superior City of Bandung. The Regional Secretary of the City of Bandung is currently experiencing difficulties in managing information relating to asset investment and management, so it is necessary to strive to manage information better, one form of its application is through information systems using computer-based information technology. In information technology there are three interrelated parts, namely: hardware, software, and database. Integrated information system architecture planning and in accordance with the organization's business goals is one of the efforts to improve services in a better direction so that it is able to compete with other organizations. In this study discusses the planning of information systems architecture management assets in the general section and equipment of the City of Bandung, a case study in the Regional Secretary (SETDA) of the City of Bandung. The discussion of this research is emphasized in four stages, namely: business architecture planning, data architecture planning, application architecture planning, and technology architecture planning. The results of the research conducted are the planning of information systems architecture management in the Regional Secretary of the City of Bandung, in the form of recommendations for the development of information systems architecture to support the improvement of public service performance and system integration into all parts of the organization.

Keywords: Business Architecture, Data Architecture, Application Architecture, Technology Architecture, EAP. 
JURNAL NUANSA INFORMATIKA

Volume 14 Nomor 2, Juli 2020

\section{Pendahuluan}

Penyelenggaraan pemerintah daerah yang lebih berorientasi kepada Otonomi Daerah, sejalan dengan pelaksanaan Undang-Undang Nomor 23 Tahun 2014 tentang Pemerintahan Daerah yang dirubah dengan Undang-Undang Nomor 9 Tahun 2015, dimana hak, wewenang, dan kewajiban daerah otonom untuk mengatur dan mengurus sendiri urusan pemerintahan dan kepentingan masyarakat setempat sesuai dengan Peraturan Perundang-undangan. Adanya pergeseran fundamental, baik secara politis, administratif, teknis maupun keuangan dan ekonomi, untuk mencermati mengadapi perubahan pengelolaan pemerintah daerah tersebut adalah perlunya menata manajemen pemerintahan yang dapat bekerja secara efesien, efektif dan ekonomis dalam penyelenggaraan pemerintah daerah telah memberikan kewenangan yang lebih luas kepada Daerah.

Seiring dengan perkembangan jaman yang telah memasuki era globalisasi dan digitalisasi, kebutuhan informasi pada suatu organisasi semakin besar. Apportunity dan uncertainty, merupakan hasil dari teknologi informasi dan sumber dari, advantage dan risk (McFarlan, 2005). Dalam sebuah organisasi SI/TI memiliki peranan penting salah satunya SI/TI merupakan sarana untuk membantu suatu organisasi dalam mewujudkan efektifita dan efisiensi integrasi antara perspektif menejemen dan operasional (proses back office dan front office), untuk meningkatkan kualitas layanan terhadap pihak yang membutuhkan, membantu meningkatkan daya saing yang semakin hari semakin ketat, dan juga membantu suatu oragnisasi dalam pengambilan sebuah kebijakan baik pada masa sekarang ataupun masa yang akan datang.

\section{Landasan Teori}

p-ISSN : 1858-3911, e-ISSN : 2614-5405

https://journal.uniku.ac.id/index.php/ilkom

Pada penelitian ini menggunakan metodelogi EAP dengan Zachman sebagai framework-nya.

\subsection{Penelitian Terkait}

Terkait dengan penelitian ini, terlebih dahulu Richard Izaac Risambessy telah melakukan penelitian dengan judul "Analisis manajemen aset daerah dalam peningkatan pendapatan asli daerah di Kabupaten Lamongan". Penelitian tersebut menggambarkan/ menganalisa manajemen aset secara komprehensif dengan tujuan untuk menemukan pendapatan asli daerah dalam peningkatan kas daerah.

\subsection{Konsep Enterprise Architecture (EA)}

Enterprise diartikan sebagai sekumpulan organisasi yang memiliki beberapa tujuan/prinsip umum, dimana sistem enterprise memungkinkan untuk mendukung struktur dan budaya organisasi yang lebih disiplin. Enterprise sendiri dapat berupa bisnis, layanan (service) atau merupakan keanggotan dari suatu organisasi, yang terdiri dari satu atau lebih usaha dan dioperasikan pada satu atau lebih lokasi (Widiatmo, 2012:15).

EA hadir dengan tujuan untuk mendeskripsikan misi dari para stakeholder mencakup parameter informasi, fungsionalitas, lokasi, organisasi dan kinerja serta menjelaskan rencana untuk membangun sistem atau sekumpulan sistem (Osvald, 2001). Konsep tentang arsitektur yang menggambarkan sebuah enterprise pertama kali muncul pada tahun 1980 dan sejak saat itulah EA terus dikembangkan oleh berbagai institusi penelitian dan pengembangan. Komponen utama dari EA yaitu: arsitektur bisnis, arsitektur informasi (data), arsitektur aplikasi dan arsitektur teknologi (Parizeau, 2002).

\subsubsection{Arsitektur Bisnis}


JURNAL NUANSA INFORMATIKA

Volume 14 Nomor 2, Juli 2020
p-ISSN : 1858-3911, e-ISSN : 2614-5405

https://journal.uniku.ac.id/index.php/ilkom
Arsitektur bisnis merupakan suatu gambaran dari sekumpulan aktivitas bisnis, data dan informasi yang ada dalam lingkungan internal dan eksternal organisasi. Arsitektur bisnis adalah representasi formal, tools serta informasi bagi profesional bisnis organisasi dalam menilai, merubah, dan merancang bisnis (Yunis, dkk., 2010:167).

\subsubsection{Arsitektur Data}

Data yang membentuk suatu kerangka tertentu disebut dengan arsitektur data.Arsitektur data harus dipandang sebagai satu bagian penting dari perencanaan EA yang mendukung pencapaian visi, misi dan tujuan-tujuan enterprise. Selain itu juga karena arsitektur data akan menjadi acuan dalam perencanaan arsitektur aplikasi dan teknologi.

"Data architecture describes the current data structures used by a business and/or its applications. This can be descriptions of data stores, data groups and data items, and mappings of data artifacts to data qualities, applications, locations and so on."

(Parmo, 2009:69)

\subsubsection{Arsitektur Aplikasi}

Arsitektur aplikasi merupakan cara komunikasi dari sekumpulan komponen-komponen melalui suatu jaringan yang saling terhubung dan menjelaskan tata letak penyebaran aplikasi, umumnya termasuk pemilihan logika aplikasi dan penyebaran kemesin server.

Arsitektur aplikasi akan mendefinisikan jenis-jenis aplikasi utama yang dibutuhkan oleh organisasi untuk mengelola data dan mendukung fungsi bisnis serta menyediakan informasi bagi pelaksana fungsi-fungsi bisnis (Wijaya, 2012:133). Arsitektur ini tidak memperhatikan kepada perancangan sistem aplikasi, namun mendefinisikan jenis-jenis sistem aplikasi yang relevan dengan enterprise dan aplikasi yang diperlukan untuk mengatur data serta menghadirkan informasi kepada aktor, manusia dan komputer yang ada di enterprise.

\subsubsection{Arsitektur Teknologi}

Arsitektur teknologi merupakan suatu gambaran umum dari struktur teknologi informasi baik arsitektur teknologi yang ada saat ini maupun arsitektur teknologi yang akan datang.

Arsitektur teknologi dirancang berdasarkan strategi perusahaan melalui pemahaman terhadap setiap strategi. Dengan memahami setiap strategi, maka arsitektur dapat dibuat dalam blueprint, kemudian menjadi landasan dalam pembuatan infrastruktur.

\subsection{Enterprise Architecture E- Government}

Konsep e-Government digambarkan atau dideskripsikan cukup beragam oleh setiap institusi internasional, baik oleh institusi pemerintah maupun swasta. Hal ini disebabkan karena e-Government memiliki prinsip-prinsip dasar yang universal, namun karena setiap negara memiliki skenario dan implementasi yang berbeda, maka definisi dari ruang lingkup e-Government pun menjadi beraneka ragam.

Konsep e-Government ini berawal dari kekhawatiran Bank Dunia dalam mengantisipasi permasalahanpermasalahan globalisasi seperti ekonomi, sosial, budaya, politik dan hukum.

"E-Government refers to the use by government agencies of information technologies (such as Wide Area Network, the Internet, and mobile computing) that have ability to transform relation with citizens, businesses, and other arms of government."

(Indrajit, 2002:2)

E-Government tidak dapat dibangun dan diterapkan hanya dengan 
JURNAL NUANSA INFORMATIKA

Volume 14 Nomor 2, Juli 2020

sekedar menyusun peraturan atau kebijakan dari pemerintah, namun memerlukan proses kerja keras yang diawali dengan perubahan paradigma yang bermuara pada perekayasaan ulang proses (business process) yang terjadi di pemerintahan. Dari sudut ini terlihat bagaimana sulit dan kompleksnya harus melakukan perancangan ulang sejumlah proses di dalam pemerintahan, terutama yang bersifat lintas sektoral atau antar departemen. Oleh karena itu agar pengembangan konsep e-Government terarah serta sejalan dengan visi dan misi organisasi dibutuhkan suatu perencanaan yang matang.

\subsection{McFarlan Strategic Grid}

McFarlan strategic grid digunakan untuk memetakan aplikasi system informasi berdasarkan kontribusinya terhadap organisasi. Pemetaan dilakukan pada empat kuadran (strategic, high potensial, key operation, dan support). Dari hasil pemetaan tersebut didapat gambaran kontribusi sebuah aplikasi system informasi terhadap organisasi dan pengembangan dimas depan (Ward dan Peppard, 2002). Keempat kuadran tersebut dapat dilihat pada gambar dibawah ini.

\begin{tabular}{|l|l|}
\hline \multicolumn{1}{|c|}{ STRATEGIC } & HIGH POTENTIAL \\
\hline $\begin{array}{l}\text { - Applications that } \\
\text { are critical to } \\
\text { sustaining future } \\
\text { business strategy }\end{array}$ & $\begin{array}{l}\text { - Applications that } \\
\text { may be important } \\
\text { in achieving future } \\
\text { success }\end{array}$ \\
\hline $\begin{array}{l}\text { Applications on which } \\
\text { the organization } \\
\text { currently depends } \\
\text { for success }\end{array}$ & $\begin{array}{l}\text { - Applications that } \\
\text { are valuable but } \\
\text { not critical to } \\
\text { success }\end{array}$ \\
\hline KEY OPERATIONAL & \multicolumn{1}{c|}{ SUPPORT } \\
\hline
\end{tabular}

Gambar 2.2 McFarlan Strategic Grid (Ward dan Peppard (2002))

\subsection{Sistem Informasi}

Organisasi yang akan membangun perencanaan arsitektur sistem informasi dapat menggunakan beberapa metodologi dan framework
p-ISSN : 1858-3911, e-ISSN : 2614-5405

https://journal.uniku.ac.id/index.php/ilkom

untuk membangun suatu arsitektur yang sesuai dengan kebutuhan organisasi. Metodologi dan framework ini berfungsi sebagai pedoman agar perencanaan EA yang dilakukan memiliki arah yang jelas dan dapat mencapai tujuan yang telah ditetapkan.

\subsubsection{Zachman Framework}

Framework dapat diartikan sebagai sejumlah pemikiran, konsep, ide atau asumsi yang digunakan untuk mengorganisasikan proses pemikiran tentang sesuatu atau situasi. Framework ini juga dapat dianggap sebagai dasar berpikir untuk mengelompokkan dan mengorganisasikan representasi sebuah perusahaan yang penting bagi manajemen perusahaan dan pengembangan sistem selanjutnya (Zachman, 1987:276).

Baris-baris pada Framework mewakili tingkat abstraksi yang digunakan untuk melakukan analisis sistem.

1. Scope (ruang lingkup): lapisan abstraksi paling tinggi, diwakili dari ide-ide dan konsep-konsep idealistis.

2. Model enterprise menggambarkan tingkat konseptualitas, dimana pemodelan awal dilakukan untuk mendefinisikan konsep bisnis yang mengimplementasikan ruang lingkup.

3. Model sistem adalah tingkat dimana objek-objek yang konseptual yang dirubah menjadi struktur-struktur logik.

4. Model Teknologi mendefinisikan objek secara fisik yang akan mewakili struktur-struktur logik.

5. Representasi detail, lapisan ini terdiri dari implementasiimplementasi penuh dari spesifikasi secara fisik untuk setiap katagori.

Aktivitas utama pengelolaan data skala enterprise yang terdapat pada kolom-kolom framework adalah : 
JURNAL NUANSA INFORMATIKA

Volume 14 Nomor 2, Juli 2020

1. Data merupakan perwujutan dari informasi.

2. Function.

3. Hardware.

4. People.

5. Time.

6. Motivation.

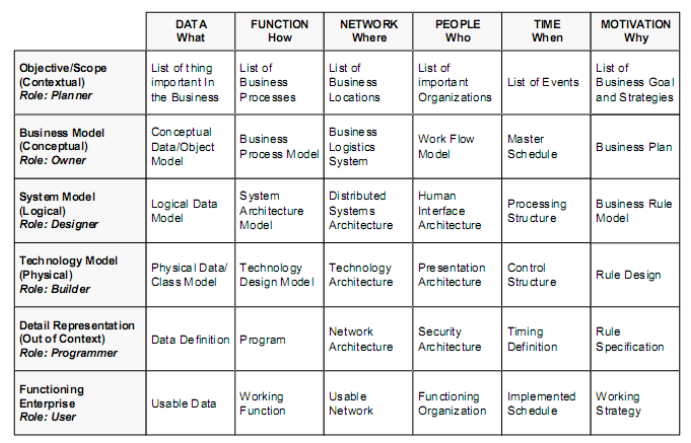

Gambar 2.3 Zachman Framework (Zachman, 1987)

\subsubsection{Enterprise Planning (EAP)}

Architecture

Enterprise Architecture Planning (EAP) merupakan proses pendefinisian arsitektur untuk menggunakan informasi guna mendukung bisnis dan rencana untuk mengimplementasikan arsitektur tersebut. Proses pendefinisian tersebut mensyaratkan EA dapat memberi dukungan terhadap kebutuhan bisnis dengan rencana implementasinya (Spewak, 1992).

\begin{tabular}{|l|l|l|l|}
\cline { 2 - 4 } \multicolumn{1}{c|}{} & \multicolumn{1}{|c|}{$\begin{array}{c}\text { DATA } \\
\text { What }\end{array}$} & \multicolumn{1}{c|}{$\begin{array}{c}\text { FUNCTON } \\
\text { How }\end{array}$} & $\begin{array}{l}\text { NETWORK } \\
\text { Where }\end{array}$ \\
\hline $\begin{array}{l}\text { Objective/Scope } \\
\text { (Contextual) } \\
\text { Role: Planner }\end{array}$ & $\begin{array}{l}\text { List of thing } \\
\text { important In } \\
\text { the Business }\end{array}$ & $\begin{array}{l}\text { List of } \\
\text { Business } \\
\text { Processes }\end{array}$ & $\begin{array}{l}\text { List of } \\
\text { Business } \\
\text { Locations }\end{array}$ \\
\hline $\begin{array}{l}\text { Business Model } \\
\text { (Conceptual) } \\
\text { Role: Owner }\end{array}$ & $\begin{array}{l}\text { Conceptual } \\
\text { Data/Object } \\
\text { Model }\end{array}$ & $\begin{array}{l}\text { Business } \\
\text { Process Model }\end{array}$ & $\begin{array}{l}\text { Business } \\
\text { Logistics } \\
\text { System }\end{array}$ \\
\hline
\end{tabular}

Gambar 2.4 Perencanaan Enterprise Architecture (Spewak, 1992)

Terdapat tujuh fase dalam EAP yang dikemukakan Spewak, dikerjakan untuk mendefinisikan dua baris pertama dan tiga kolom pertama dari Zachman Framework. Tujuh fase tersebut terbagi dalam empat tahapan yang menggambarkan urutan pengerjaan metodologi EAP.
p-ISSN : 1858-3911, e-ISSN : 2614-5405

https://journal.uniku.ac.id/index.php/ilkom

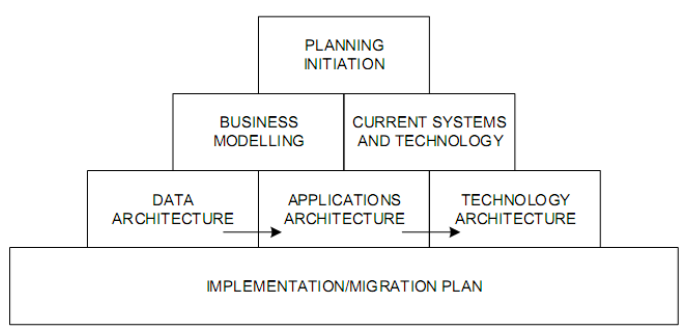

Gambar 2.5 Metodologi EAP (Spewak, 1992)

\subsubsection{EAP menggunakan Framework Zachman}

Zachman Framework merupakan salah satu metode EAP yang banyak digunakan diseluruh dunia dalam perancangan sistem dimana drsitekturidalam metode ini perencanaan dilakukan dengan langkah-langkah yang sistematis, mudah dipahami dan dapat dijadikan kontrol untuk pengembangan sistem informasi ke depan. Hasil penelitian ini berupa blue print rancangan sistem yang dipetakan didalam bentuk matrik Zachman yang dilihat dari sudut pandang Planner dan Owner.

Sebelumnya banyak juga penelitian yang menggunakan metode EAP yang menggunakan Zachman sebagai Framework-nya. Dalam penelitian ini penulis mencoba menggunakan metode EAP dan Zachman sebagai Framework-nya untuk membuat perancangan arsitektur sistem informasi menejemen asset di SETDA Kota Bandung.

\subsection{Busines Process Modeling Notation (BPMN)}

Stephen A. White dalam bukunya yang berjudul BPMN Modeling and Reference Guide Understanding and Using BPMN menjelaskan bahwa BPMN merupakan salah satu metode pemodelan proses bisnis yang dikeluarkan oleh BPMI (Business Process Management Initiative) dan model yang merupakan tahapan awal dalam rangkaian seluruh aktivitas 
JURNAL NUANSA INFORMATIKA

Volume 14 Nomor 2, Juli 2020

pemodelan proses bisnis. BPMN merupakan tool untuk memodelkan proses bisnis yang dirilis oleh BPMI pada bulan mei tahun 2004.

BPMN menyediakan BPD (Business Process Diagram), yang berlandaskan pada teknik flowchart yang digunakan untuk membuat model grafis dari proses bisnis.

\subsection{Unified Modeling Laanguage (UML) \\ Unified Modeling Language}

(UML) adalah bahasa spesifikasi standar untuk mendokumentasikan, menspesifikasikan, dan membangun sistem perangkat lunak. Unified Modeling Language (UML) adalah himpunan struktur dan teknik untuk pemodelan desain program berorientasi objek (OOP) serta aplikasinya (Adi Nugroho,2009). UML adalah metodologi untuk mengembangkan sistem OOP dan sekelompok perangkat tool untuk mendukung pengembangan sistem tersebut [Adi Nugroho,2009]. UML mulai diperkenalkan oleh Object menejemen Group, sebuah organisasi yang telah mengembangkan model, teknologi, dan standar OOP sejak tahun 1980-an (Adi Nugroho,2009). Sekarang UML sudah mulai banyak digunakan oleh para praktisi OOP (Adi Nugroho,2009). UML merupakan dasar bagi perangkat (tool) desain berorientasi objek dari IBM (Adi Nugroho,2009).

UML adalah suatu bahasa yang digunakan untuk menentukan, memvisualisasikan, membangun, dan mendokumentasikan suatu sistem informasi. UML dikembangkan sebagai suatu alat untuk analisis dan desain berorientasi objek oleh Grady Booch, Jim Rumbaugh, dan Ivar Jacobson. Namun demikian UML dapat digunakan untuk memahami dan mendokumentasikan setiap sistem informasi. Penggunaan UML dalam industri terus meningkat. Ini merupakan
p-ISSN : 1858-3911, e-ISSN : 2614-5405

https://journal.uniku.ac.id/index.php/ilkom

standar terbuka yang menjadikannya sebagai bahasa pemodelan yang umum dalam industri peranti lunak dan pengembangan sistem.

\subsubsection{Diagram UML}

UML menyediakan 10 macam diagram untuk memodelkan aplikasi berorientasi objek, yaitu :

1. Use Case Diagram untuk memodelkan proses bisnis.

2. Conceptual Diagram untuk memodelkan konsep-konsep yang ada di dalam aplikasi.

3. Sequence Diagram untuk memodelkan pengiriman pesan (message) antar objects.

4. Collaboration Diagram untuk memodelkan interaksi antar objects.

5. State Diagram untuk memodelkan perilaku objects di dalam sistem.

6. Activity Diagram untuk memodelkan perilaku Use Cases dan objects di dalam system.

7. Class Diagram untuk memodelkan struktur kelas.

8. Object Diagram untuk memodelkan struktur object.

9. Component Diagram untuk memodelkan komponen object.

10. Deployment Diagram untuk memodelkan distribusi aplikasi.

\subsubsection{Use Case Diagram}

Use case diagram menggambarkan fungsionalitas yang diharapkan dari sebuah sistem. Yang ditekankan adalah "apa" yang diperbuat sistem, dan bukan "bagaimana". Sebuah use case merepresentasikan sebuah interaksi antara aktor dengan sistem. Use case merupakan sebuah pekerjaan tertentu, misalnya login ke sistem, mengcreate sebuah daftar belanja, dan sebagainya. Seorang/sebuah aktor adalah sebuah entitas manusia atau mesin yang berinteraksi dengan sistem untuk melakukan pekerjaan-pekerjaan tertentu. Sebuah use case juga dapat meng-extend use case lain dengan 
JURNAL NUANSA INFORMATIKA

Volume 14 Nomor 2, Juli 2020

behaviour-nya sendiri. Sementara hubungan generalisasi antar use case menunjukkan bahwa use case yang satu merupakan spesialisasi dari yang lain. Penggambaran Use case diagram dapat di lihat dalam gambar 2.6 di bawah ini.

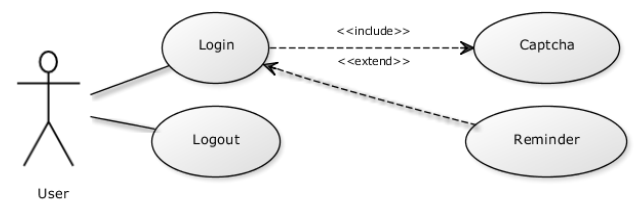

Gambar 2.6 Contoh use case diagram

(Djumadi Abdillah, 2008)

Extend adalah Relasi use case tambahan ke sebuah use case dimana use case yang ditambahkan dapat berdiri sendiri walau tanpa use case tambahan itu. Sedangkan Include adalah Relasi use case tambahan ke sebuah use case dimana use case yang ditambahkan memerlukan use case ini untuk menjalankan fungsinya.

\subsubsection{Class Diagram}

Class diagram merupakan diagram yang selalu ada dipermodelan sistem berorientasi objek. Class diagram menunjukkan hubungan antar class dalam sistem yang sedang dibangun dan bagaimana mereka saling berkolaborasi untuk mencapai suatu tujuan. Penggambaran class diagram dapat di lihat dalam gambar 2.9 dibawah ini.

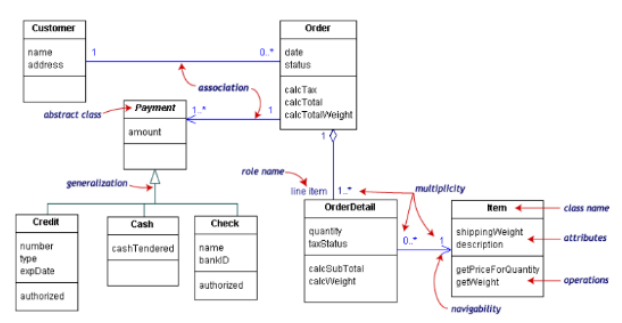

Gambar 2.7 Contoh class diagram (Dharwiyanti, Satria Wahono, 2010)

\subsection{Value Chain}

Untuk mendapatkan pengertian yang lebih baik tentang aktifitas-aktifitas
p-ISSN : 1858-3911, e-ISSN : 2614-5405

https://journal.uniku.ac.id/index.php/ilkom

perusahaan yang memberikan keunggulan kompetitif dan menciptakan nilai bagi shareholder, kita dapat memilah-memilih system bisnis menjadi sebuah urut-urutan aktifitas yang menghasilkan nilai (value). Hasil analisis Value Chain suatu organisasi digunakan untuk identifikasi peluang pemanfaatan SI/TI yang dapat meningkatkan keunggulan kompetitifnya. Diagram value chain terlihat pada gambar 2.10.

Porter mendeskripsikan dua kategori aktifitas dari value chain sebagai berikut:

1. Primary activities, (Terkadang disebut sebagai line function) yang melibatkan pembuatan produk, memasarkannya kepda pembeli, dan memberi dukungan pasca penjualan.

2. Secondary activities, (terkadang disebut staff atau fungsi overhead) membimbing organisasi sebagai keseluruhan dengan menyediakan infrastruktur atau input yang mengijinkan primary activities berjalan pada tempatnya.

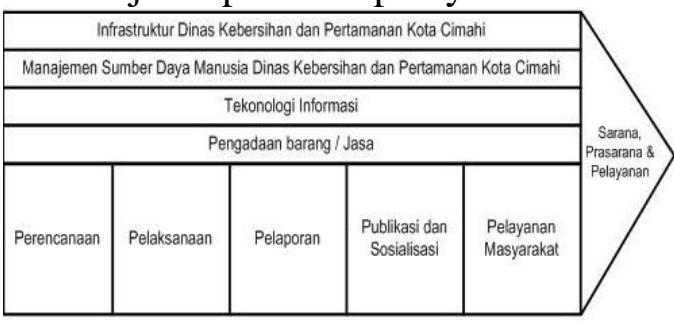

Gambar 2.8 competitive Advantage (Dinas Kebersihan Kota Cimahi 2011)

\section{Metodologi Penelitian}

Metodologi yang digunakan pada tesis ini mengikuti acuan / pedoman sesuai dengan fase yang ditetapkan pada buku Enterprise Architecture Planning karangan Steven H. Spewak. Urutan fase digambarkan pada gambar 3.2.

Metodologi tersebut merupakan langkah-langkah yang dilakukan dalam pengembangan arsitekur enterprise. Setiap langkah diilustrasikan dalam setiap kotak dan ada sedikit ringkasan 
JURNAL NUANSA INFORMATIKA

Volume 14 Nomor 2, Juli 2020

singkat dari setiap tahap yang akan dilakukan

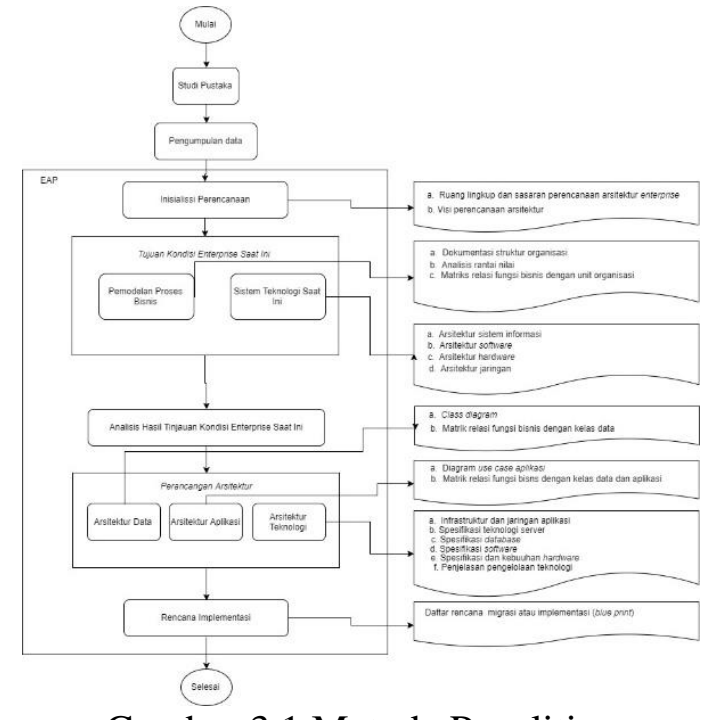

Gambar 3.1 Metode Penelitian

\section{Identifikasi Fungsi Bisnis}

Tahapan ini merupakan tahap untuk melakukan perencanaan terhadap proses bisnis SETDA Kota Bandung secara keseluruhan. Adapun tool yang digunakan untuk membuat perencanaan arsitektur bisnis ini yaitu analisis rantai nilai (value chain). Berdasarkan struktur organisasi SETDA Kota Bandung, maka dilakukan pendefinisian sub proses bisnis berupa aktivitas-aktivitas yang lebih kecil. Adapun proses bisnis yang terjadi di SETDA Kota Bandung dapat dikategorikan menjadi dua yaitu proses bisnis utama dan proses bisnis pendukung yang terlihat seperti pada Gambar 4.1.

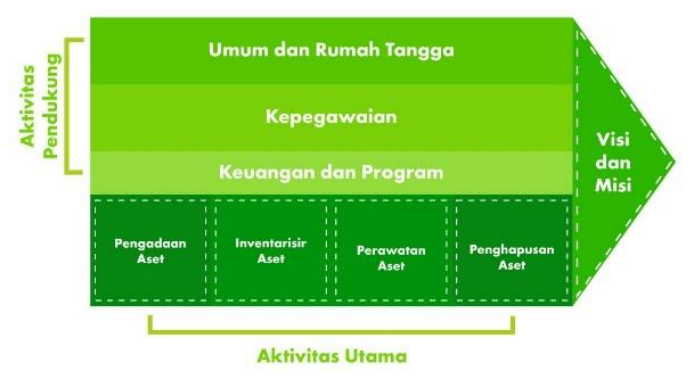

Gambar 4.1 Value Chain SETDA Kota Bandung

\subsection{Analisis Matriks}

Terakreditasi SINTA 5
p-ISSN : 1858-3911, e-ISSN : 2614-5405

https://journal.uniku.ac.id/index.php/ilkom

4.1.1. Proses Bisnis Manajemen Aset Proses bisnis ini dilakukan oleh Bagian Umum dan Perlengkapan, sub bagian perlengkapan mendata seluruh aset yang dimiliki oleh SETADA Kota Bandung. Pendataan tersebut dilakukan agar seluruh aset yang berada di SETDA Kota Bandung tidak ada yang hilang ataupun yang rusak, Pendataan tersebut perlu adanya karna sub bagian perlengkapan disini yang bertanggung jawab dapat mengetahui aset mana saja yang harus di perbaiki dan yang harus diganti dengan yang lebih baru. Semua ini dilakukan untuk menunjang kinerja pemerintah kota bandung khususna yang berada di lingkungan SETDA Kota Bandung. Aktivitas-aktivitas dari proses pengadaan Aset dijelaskan pada Tabel 4.1, aliran proses bisnis pendataan aset dijelaskan pada Gambar 4.2, dan matriks fungsi bisnis pendataan aset dengan unit organisasi dijelaskan pada Tabel 4.2.

Adapun alur proses bisnis pedataan aset pada SETDA Kota Bandung adalah seperti gambar di bawah ini :

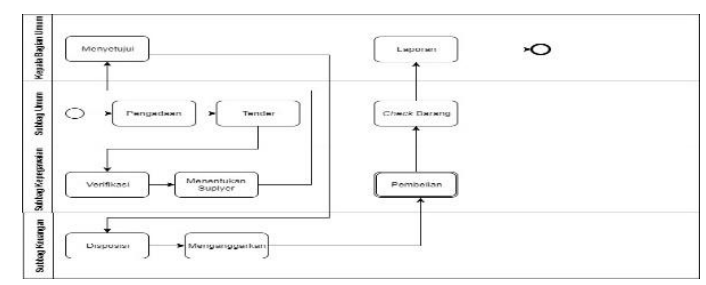

Gambar 4.2 Alur proses pendataan Aset

4.1.2. Pelayanan Pemeliharaan aset tidak bergerak maupun bergerak. Pelayanan pemeliharaan aset ini dilakukan secara berkala oleh sub bagian perlengkapan, sub bagian menerima laporan bahwa ada aset yang harus diperbaiki atau di maintenance, lalu sub bagian membuat anggaran untuk memfasilitasi atau mengakomodir pemeliharaan itu, pemeliaraan aset terebut biasanya dilempar kepada pihak ke-3 dengan proses tender. Jadi pemerintah Kota Bandung bekerja sama 
JURNAL NUANSA INFORMATIKA

Volume 14 Nomor 2, Juli 2020

dengan pihak swasta untuk memelihara aset tersebut.

Adapun alur proses bisnis pelayanan pemeliharan aset bergerak maupun tidak bergerak di lingkungan SETDA Kota Bandung adalah seperti gambar di bawah ini :

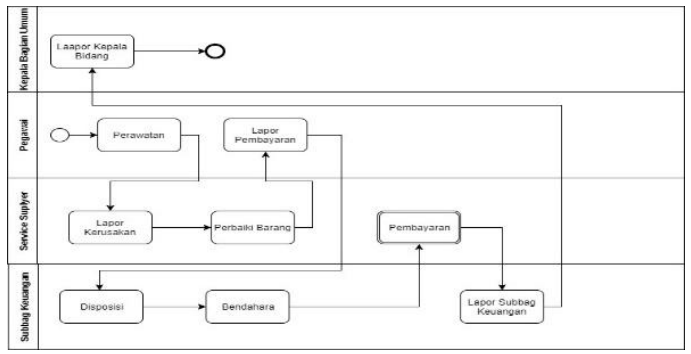

Gambar 4.3 Alur Proses Bisnis Pemeliharaan Aset

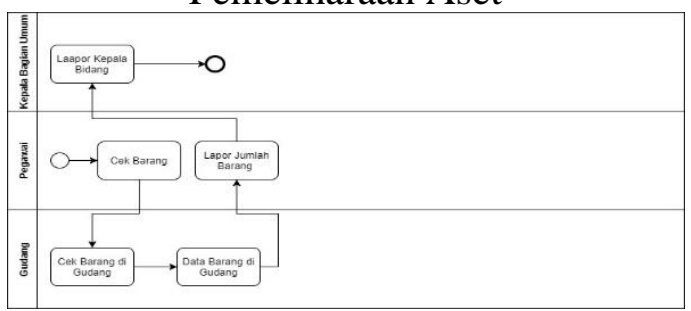

Gambar 4.4 Alur Proses Bisnis Iventarisir Aset

4.1.3. Proses Bisnis Penghapusan aset Proses bisnis ini dilakukan oleh Sub bagian Umum dan Rumah Tangga, diawali dengan mendata aset yang bergerak maupun yang tidak, kemudian apabila terdapat aset yang sudah tua atau tidak bisa di pergunakan lagi, maka aset tersebut dapat di hapuskan dengan cara dilelang ke SKPD lain atau dengan cara di hibahkan. Selanjutnya bagian perlengkapan memberi laporan kepada Kepala Bagian Umum dan Perlengkapan yang kemudian akan di teruskan untuk dilaporkan kepada Sekertaris Daerah, dimana Sekertaris daerah akan mempertangung jawabkan aset Kota Bandung kepada Walikota Bandung. Kemudian dilaporkan jua kepada Inspektorat dan BPK. Untuk detil aktivitas pada proses bisnis di bagian
p-ISSN : 1858-3911, e-ISSN : 2614-5405

https://journal.uniku.ac.id/index.php/ilkom

penghapusan aset dibuat dalam bentuk tabel di bawah ini.

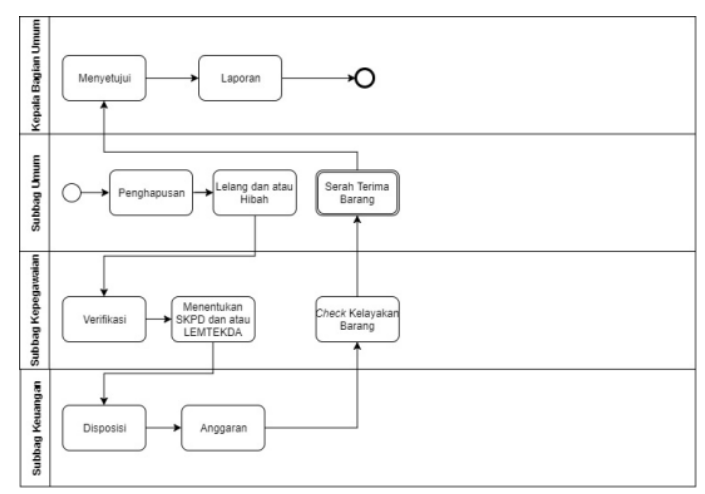

Gambar 4.5 Alur Proses Bisnis

Penghapusan Aset

4.2 Perancangan Arsitektur Data

Pada tahap ini dilakukan penetapan target perencanaan arsitektur data yaitu membuat gapanalisys arsitektur data, mendefinisikan kelaskelas data yang akan digunakan pada perencanaan arsitektur aplikasi. Model yang digunakan dalam perencanaan arsitektur data menggunakan class diagram yang menggambarkan relasi antar data dan entitas yang ada dalam sistem informasi pelayanan kesejahteraan sosial. Adapun yang dilakukan dalam perencanaan arsitektur data meliputi:

1. Membuat gap analysis arsitektur data.

2. Menganalisis kelas-kelas data.

3. Membuat matriks fungsi bisnis dengan kelas data.

4. Membuat pemodelan class diagram.

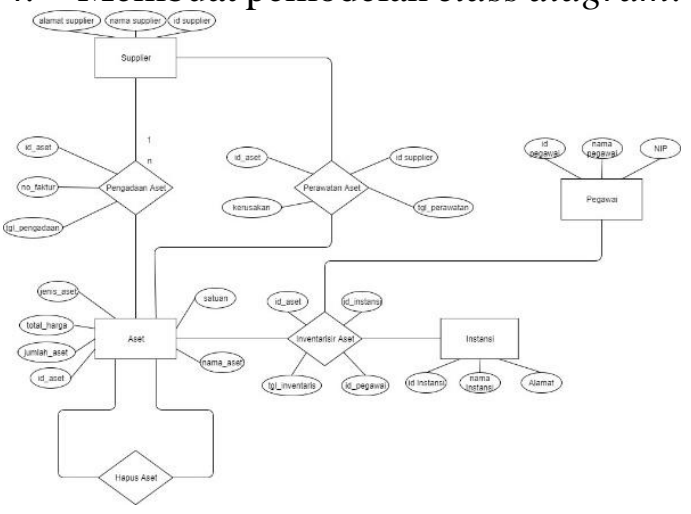


JURNAL NUANSA INFORMATIKA

Volume 14 Nomor 2, Juli 2020

Gambar 4.6 Entity Relationship Diagram

\subsubsection{Pemodelan Class Diagram}

Pemodelan class diagram bertujuan untuk mendefinsikan relasi antara class dari class data yang sudah didefinisikan sebelumnya. Adapun pemodelan class diagram dapat dilihat pada Gambar 4.7

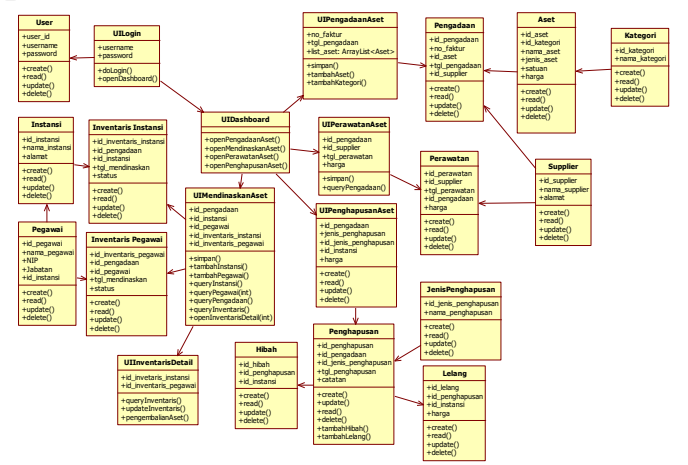

Gambar 4.7 Class Diagram

\subsection{Perancangan Arsitektur Teknologi}

Pada tahap ini dilakukan pendefinisian platform teknologi yang dapat menunjang lingkungan bagi aplikasi yang akan mengelola data dan mendukung fungsi-fungsi bisnis. Adapun langkah-langkah yang akan dilakukan dalam menentukan arsitektur teknologi yaitu sebagai berikut:

1. Membuat gap analysis arsitektur teknologi.

2. Membuat infrastruktur dan arsitektur teknologi jaringan.

3. Menentukan spesifikasi teknologi server.

4. Menentukan spesifikasi database.

5. Menentukan spesifikasi software.

6. Menentukan spesifikasi harware.

7. Membuat pengelolaan arsitektur teknologi.

4.4 Perancangan Peluang dan Solusi Pada tahap ini dilakukan analisis manfaat yang diraih dari arsitektur sistem informasi yang telah berhasil dibuat. Tahapan ini merupakan peluang dan solusi bagi organisasi untuk memilih dan menentukan arsitektur sistem
p-ISSN : 1858-3911, e-ISSN : 2614-5405

https://journal.uniku.ac.id/index.php/ilkom

informasi yang akan diimplementasikan dengan terintegrasi dan berkesinambungan dimasa yang akan datang.

Adapun solusi dari arsitektur sistem informasi yang akan dibangun yakni sebagai berikut:

1. Aplikasi yang dibangun harus menggunakan database yang terstruktur dan terintegrasi.

2. Distribusi data dan perangkat lunak harus secara terpusat dengan security yang berlapis dan berjenjang.

3. Aplikasi yang dibangun harus dapat diakses melalui jaringan internet, $V P N$ dan jaringan lokal (LAN).

\section{Saran dan Kesimpulan}

\subsection{Kesimpulan}

Berdasarkan hasil pembahasan tesis sesuai dengan metodologi penelitian yang digunakan maka dapat diambil beberapa kesimpulan sebagai berikut:

1. Proses analisis dari sistem informasi Aset di Bagian Umun yang ada di SETDA Kota Bandung menggunakan BPMN yang meliputi empat bagian proses yaitu pengadaan, inventarisir, perawatan dan penghapusan aset, sesuai alur SOP yang telah dibuat sebelumnya.

2. Hasil dari perencanaan arsitektur enterprise sistem informasi aset di Bagian Umun dan perlengkapan di SETDA Kota Bandung menghasilkan rancangan class diagram yang terdiri dari 10 sub sistem berupa aplikasi yang terintegrasi ke seluruh bagian yang terkait dalam organisasi yang dapat menunjang proses bisnis baik yang utama maupun yang aktivitas bisnis pendukung.

3. Dengan adanya perencanaan pembangunan sistem yang baru, maka SETDA Kota Bandung dapat mengimplementasikannya secara 
JURNAL NUANSA INFORMATIKA

Volume 14 Nomor 2, Juli 2020
p-ISSN : 1858-3911, e-ISSN : 2614-5405

https://journal.uniku.ac.id/index.php/ilkom bertahap sesuai dengan jadwal dan target waktu yang telah tentukan, yaitu selama delapan bulan. Dengan demikian semua proses pelayanan aset di bagian umun dan perlengkapan sudah menggunakan sistem informasi sehingga visi dari perencanaan arsitektur tercapai

\subsection{Saran}

Saran yang dapat disampaikan kepada organisasi agar hasil penelitian ini bermanfaat dalam menunjang proses bisnis aset di bagian umun dan perlengkapan diantaranya:

1. Pemerintah dan manajemen SETDA Kota Bandung harus memiliki komitmen serta mendukung sepenuhnya terhadap pengembangan dan implementasi hasil perencanaan arsitektur sistem informasi agar keberhasilan dalam penerapan sesuai dengan harapan organisasi.

2. Semua bagian yang terkait dalam organisasi agar mempunyai komitmen untuk mendukung penerapan dan implementasi dari sistem yang dibangun sehingga tujuan sistem yang terintegrasi dapat berjalan dengan baik dan akan membantu meningkatkan kinerja optimal.

3. Dalam pelaksanaan implementasi dan penerapan sistem informasi semua bagian yang terkait dalam organisasi harus diberi penjelasan dan pemahaman yang cukup dan memadai sehingga tidak ada sistem yang tidak digunakan karena kurang pahamnya menggunakan sistem.

4. Harus ada evaluasi terhadap rencana pengembangan dan implementasi sistem yang telah disetujui dan digunakan.

5. Perlu adanya SOP yang mengatur proses bisnis mulai dari tahap pengadaan samapai tahap terakhir yaitu penghapusan aset.

\section{DAFTAR PUSTAKA}

[1] Parmo, Christopher L. The use of Enterprise Architecture, IT Strategy and IT Governance at StatoilHydro. Norwegian University of Science and Technology, Department of Computer and Information Science. Norwegia. 2009.

[2] Sanny, dkk. Entreprise Architecture Planning Sistem Informasi Puskesmas Pasir Kaliki. UNIKOM, Bandung. 2010.

[3] Spewak, Steven H. Enterprise Architecture Planning (Developing a Blueprint for Data, Application and Technology). John Wiley \& Sons, Inc. 1992.

[4] Steinhoff, D. The World of Business. McGraw - Hill Book Company. United States. 1979.

[5] Supriatna, Ade. Pembuatan Cetak Biru (Blue Print) Penomoran Penduduk Nasional Secara Elektronik (E-National Identity Card) Dalam Rangka Akurasi Data Untuk Keperluan Daftar Pemilih Tetap Pada Pemilu Di Indonesia Tahun 2014. ISSN: 1979-2328, Seminar Nasional Informatika. 2009.

[6] Wijaya, Dedy R. Rencana Induk Pengembangan Sistem Informasi Politeknik Telkom Menggunakan Enterprise Architecture Planning (EAP). ISSN: 2302-1896, Konferensi Nasional ICT-M Politeknik Telkom (KNIP). 2012.

[7] Zachman, J. A., A Framework For Information Systems Architecture. IBM System Journal, Vol. 26, No. 3. 1987 